\title{
MARÍA MARCHIANO
}

Laboratorio para el Estudio de la Experiencia Musical (LEEM) - Facultad de Bellas Artes (FBA) - Universidad Nacional de La Plata (UNLP).

maria.marchiano@hotmail.com

\section{Reseña de libro}

\section{Un modelo corporeizado de interacción expresiva con la música}

Reseña de:

Leman, Marc (2016). The Expressive Moment. How Interaction (with Music) Shapes Human Empowerment. Massachusetts: The MIT Press, 25I PP. ISBN 9780262034937.

El estudio sistematizado sobre la experiencia del ser humano con la música es de larga data. La idea de la existencia de una mente musical surge con la psicología de la música a mediados del siglo XIX (Fernández y Casas, 2016), que en la segunda década del siglo pasado es sepultada por la concepción mecanicista del programa conductista que niega o reduce los procesos mentales a su mínima expresión. Desde 1960 se desarrolla un nuevo modelo cognitivista que compara el funcionamiento de la mente humana con el procesamiento de la información de una computadora, definido por mecanismos "desde arriba" (top-down) que dan lugar a la construcción de representaciones mentales de base lingüística (Pozo, 1989). Alrededor de 1980 surgen las ciencias cognitivas hoy denominadas clásicas que estudian la experiencia musical desde un enfoque objetivista sin tener en cuenta ni el contexto ni el rol del cuerpo en la interacción (Martínez, 2014). A este panorama se suma una década después la perspectiva evolucionista, que considera la función de la música en el aprendizaje del manejo de las incertidumbres de la vida en sociedad y debate sobre su origen biológico (profundo, centrado en el vínculo entre los rasgos acústicos estructurales del sonido y los afectos y motivaciones humanos) y cultural (más superficial, que explica su heterogeneidad, sus múl-

Epistemus - Revista de estudios en Música, Cognición y Cultura. ISSN 1853-0494

http://revistas.unlp.edu.ar/Epistemus

Epistemus es una publicación de SACCoM (www.saccom.org.ar).

Vol. 4. No 2 (2016) | 113-120

Recibido: 04/10/2016. Aceptado: 21/10/2016.

Esta obra está bajo una Licencia Creative Commons Atribución - No Comercial - Sin Obra Derivada 4.0 Internacional de Creative Commons. Puede copiarla, distribuirla y comunicarla públicamente siempre que cite su autor y la revista que lo publica (Epistemus - Revista de estudios en Música, Cognición y Cultura), agregando la dirección URL y/o un enlace a este sitio: http://revistas.unlp.edu.ar/Epistemus. No la utilice para fines comerciales y no haga con ella obra derivada.

La licencia completa la puede consultar en https://creativecommons.org/licenses/by-nc-nd/4.0/ 
tiples valoraciones y su apariencia de intencionalidad) (Cross, 2010). Finalmente, sobre el cambio de milenio el interés de las ciencias cognitivas viró hacia el rol del cuerpo, en contraposición (enfoque corporeizado radical) o en colaboración con las representaciones mentales (DiPaolo y Thompson, 2014), y hacia la acción y la intención, retomando ideas del pragmatismo filosófico al postular que la cognición puede ser comprendida en sí misma como una forma de enacción que nos permite "actuar significativamente" un mundo (enact) y no como una creadora de modelos posibles a partir de los que luego se actúa (Engel, 2010).

Este breve paneo del panorama de las ciencias cognitivas tiene el objetivo de refrescar sus intereses y posturas generales para encuadrar la trayectoria del pensamiento de Marc Leman en El momento expresivo y contextualizar su apropiación de algunos conceptos e ideas de estos enfoques que sintetizaré en este artículo de reseña.

Desde sus inicios, Leman ha sido un exponente fundamental del enfoque ecológico de la cognición musical corporeizada, concibiendo al cuerpo como un mediador entre el ambiente y la formación del significado (Leman, 2011) y estudiando el involucramiento del cuerpo en diversas actividades: la escucha corporeizada, las articulaciones expresivas de los instrumentistas, la alineación del cuerpo con la música en actividades cotidianas, los movimientos espontáneos de baile, las posibilidades multimodales de consulta de música por parte de usuarios a través de tecnologías de mediación, entre otros. En El momento expresivo Leman se encarga por un lado de situar su pensamiento de la corporalidad en la interacción con la música bajo un enfoque enactivo y comunicativo, y por el otro de articular sus ideas ligadas a la segunda generación de las ciencias cognitivas con nociones de modelos clásicos que parecían abandonados y que acá aparecen sumamente resignificados. El libro tiene el objetivo de definir los principios y las causas del empoderamiento que genera la música en el ser humano, estudiando los procesos pre-reflexivos rápidos y dinámicos de la interacción musical. Leman propone considerar las representaciones conscientes y el pensamiento cognitivo lingǘ́stico como una extensión de los mecanismos sensorio-motores que definen y determinan las interacciones corporeizadas.

Leman define al momento expresivo como "el punto crítico en el que respondemos rápidamente ante una situación” (p. ix). El capítulo 1 introduce el concepto de interacción, definido desde un enfoque pragmático: las interacciones del ser humano con su entorno mantienen su curso gracias a mecanismos corporales y gestos expresivos que marcan una instancia reactiva inmediata y pre-reflexiva, oponiéndose a la idea de exclusividad de los modelos predictivos internos que involucran procesos cognitivos mentales en la construcción del proceso interactivo y que marcan una instancia reflexiva basada en estructuras semánticas. La interacción musical es expresiva porque el sistema sensorio-motor captura las posibilida- 
des de acción (affordances) ${ }^{1}$ percibidas corporizadamente en el entorno, que inducen a actuar de determinadas formas. Las acciones reactivas que generan inician la interacción y permiten entablar la comunicación. La expresión es una cualidad del movimiento humano que intenta provocar una respuesta expresiva (gestos, actitudes y matices de las articulaciones motoras), y su estudio implica una búsqueda sobre las formas de establecer los significados y no sobre los significados mismos.

En los capítulos 2, 3 y 4 se profundiza sobre el contexto y los elementos que componen la interacción expresiva con la música.

El capítulo 2 permite una comprensión cabal del enfoque pragmático, cristalizado en un modelo de comunicación para el intercambio de información musical que transforma y profundiza el modelo semántico de emisor-mensaje-receptor. El problema central que Leman identifica en el traslado del modelo clásico de comunicación al campo musical es la naturaleza lingüístico-proposicional del mensaje, cuya codificación y decodificación implica una instancia de conceptualización semántica que contradice la instantaneidad del procesamiento durante las interacciones expresivas con la música y que exige concebirla como un discurso que carga un significado. El modelo pragmático, en cambio, propone estudiar la comunicación desde la base misma de la interacción. Su éxito es el resultado del involucramiento de los agentes en la experiencia musical en tiempo real y se establece por un bucle de la información entre patrones (energía sonora, movimientos, activaciones cerebrales) y estados intencionales (metas de acción que tienen la intención de generar un resultado determinado). El emisor codifica ideas musicales y estados intencionales en patrones de movimiento, que en el caso del músico generan patrones musicales. El receptor decodifica esos patrones musicales en estados intencionales o en ideas musicales a través de patrones de movimiento. Estos roles son intercambiados continuamente durante la interacción dependiendo de la dirección de la información: un agente es emisor cuando codifica y receptor cuando decodifica. El bucle se origina en posibilidades de acción codificadas en los patrones musicales, que inducen movimientos sensorio-motores particulares ligados a las características estructurales de la energía sonora. Esas acciones reactivas generan determinados resultados sensoriales percibidos por el agente en el curso de la interacción, cuya asociación repetida crea patrones cerebrales que dan lugar a los esquemas sensorio-motores que permiten la predicción. Este modelo de comunicación es el marco en el que se realizan las interacciones musicales y es profundizado a lo largo del libro.

El capítulo 3 estudia la sensibilidad humana a las posibilidades expresivas de acción del entorno, regulada por el sistema expresivo bumano. Para Leman la expresión tiene un origen tanto biológico como cultural. Como signo biológico es un

1. La complejidad del concepto de affordances dificulta su traducción directa al español. Según el enactivismo, las affordances son "oportunidades para articular y poner la articulación en relación a nuestras disposiciones expresivas disponibles” (Leman, 2016, p. 3). 
mecanismo innato basado en reflejos de atracción y repulsión que no precisa de un procesamiento mental para ser percibido como tal y que despierta una urgencia de interacción. El aprendizaje de estas respuestas gestuales naturales codifica e internaliza la expresión en forma de esquemas sensorio-motores, convirtiéndola en un signo cultural y generando una expresión común compartida por la población que permite la adaptación de los individuos a los entornos sociales. Las características comunes del sistema expresivo en una población generan patrones de movimiento similares entre sus miembros, generando similitudes tanto entre las respuestas expresivas espontáneas a la música como entre los mecanismos-espejo expresivos de la percepción corporeizada (que decodifican las posibilidades de acción expresivas del flujo sonoro) y los de los movimientos expresivos del músico (codificación expresiva). Además, Leman establece un vínculo entre la intención en la codificación de la expresión de un intérprete musical, su plan de acción para realizarla y los movimientos expresivos que la generan.

En el capítulo 4 Leman define a la música como el resultado de la interacción entre los patrones de sonido y su procesamiento basada en dos mecanismos. El mecanismo de procesamiento "desde abajo" (bottom-up) trabaja con la organización interna disponible en los patrones de sonido, que emerge ante el sistema expresivo humano y da lugar a la percepción de objetos sonoros globales. Esta emergencia de los patrones sonoros surge por la necesidad del hombre de transformar la complejidad del entorno en unidades posibles de manejar que Leman define, desde una postura enactiva, en términos de metas de acción, convirtiendo el patrón sonoro en un patrón intencional percibido por su funcionalidad para la acción. Esta dinámica entre organización y emergencia de los patrones sonoros es lo que permite la predicción del flujo sonoro. El procesamiento "desde arriba" es una instancia de mediación construida sobre comportamientos aprendidos (la atención, el movimiento, el conocimiento y la emoción) que involucra modelos predictivos que le dan más peso a ciertos canales sensoriales que a otros. Estos mediadores compartidos socialmente contribuyen en la selección de organizaciones sonoras (inherentes a la organización interna y externa de los patrones de energía acústica) que determinan el entorno cultural común de una población o repertorio.

Entre los capítulos 5 y 8 se estudia el comportamiento de la estructura cognitiva definida como arquitectura cognitivo-motivacional con el objetivo de descifrar el efecto empoderador de la música resultante de las dinámicas de interacción.

Los capítulos 5 y 6 abordan los procesos cognitivos que manejan las propiedades estructurales y predictivas de los patrones expresivos.

El capítulo 5 analiza la sincronía interactiva (entrainment), considerando a los patrones recurrentes que marcan la emergencia de un beat en la música y al comportamiento repetitivo humano como ritmos oscilatorios. El cuerpo humano posee una resonancia motora (un rango de frecuencias de oscilación en el que el ritmo oscilatorio es más fuerte) que es reinyectada en el repertorio en forma de tempos musicales, convirtiéndose en posibilidades de acción que los individuos 
de una población perciben en la música como emergencias al poder alinear fácilmente sus movimientos por la disposición natural de su sistema motor. Esta sincronización entre los movimientos humanos y los ritmos musicales constituye un sistema de oscilación rítmica acoplada que da lugar a la sincronía interactiva. Leman diferencia tres mecanismos sensoriomotores: encontrar el beat implica el establecimiento de un esquema sensorio-motor que prediga el flujo musical, mantener el beat es más sencillo porque el esquema ya establecido se usa como referencia para pequeños ajustes, y ser el beat implica un alineamiento de la música al movimiento humano (posible con tecnologías de mediación). La sincronía interactiva es un componente importante de la interacción con la música porque genera un efecto de satisfacción (agencia) como resultado de la sensación de control dada por la predicción correcta del tempo, aporta al empoderamiento dado que la sincronización disminuye el costo de energía, y tiene un valor biológico en tanto permite una relación estable con el entorno.

En el capítulo 6 Leman explica el mecanismo que permite la anticipación del flujo expresivo de patrones musicales: el modelo predictivo, cuya unidad de análisis son los esquemas sensorio-motores creados por la activación temporal simultánea de las zonas cerebrales vinculadas a comandos motores y resultados sensoriales percibidos, estableciendo un bucle entre acción y percepción. Leman distingue entre dos mecanismos: el modelo de predicción inverso (encargado de proveer comandos motores que generen los resultados sensoriales deseados y de comparar la predicción de la respuesta esperada con la respuesta real percibida, usando los errores de predicción para adaptar el modelo para futuras interacciones) y el modelo de predicción hacia adelante (que simula de patrones de movimiento aún no realizados, permitiendo anticipar sus resultados sensoriales). En la interacción musical ambos modelos se fusionan dando lugar a un modelo hibrido, en el que la automatización de las acciones que generan tanto patrones sonoros, alineaciones o expresiones de lapsos temporales breves (basada en el modelo "hacia adelante" ${ }^{\text {) }}$ permite el aprovechamiento de recursos cognitivos (basados en el proceso de retroalimentación del modelo inverso en tiempo real) para el monitoreo de expresiones temporalmente extensas. Leman define tres niveles de expresión constituyentes del patrón musical: la articulación, la co-articulación (ambos susceptibles de ser simulados y automatizados) y los arcos largos de expresión (posibles sólo a través de la retroalimentación).

En los capítulos 7 y 8 se profundiza el análisis del polo motivacional del proceso interactivo.

El capítulo 7 introduce la idea de alineación expresiva como homeostasis o loop cognitivo-motivacional: un proceso de transición continua entre el procesamiento del entorno y los estados intencionales, energéticos y afectivos internos que genera gestos expresivos en alineación con patrones musicales (perspectiva subjetiva)

2. Forward model en el original. 
y que corre la mirada de la simple coincidencia de patrones (perspectiva objetiva, por ejemplo de la sincronía interactiva). Leman establece tres vínculos entre formas específicas de procesamiento y estados. Por un lado, el estado de agencia es el resultado de la predicción intencional de patrones sonoros que da lugar a un sentimiento de control y de satisfacción ante la fiabilidad de la maquinaria predictiva, generando un afecto pro-social ante el potencial uso del mecanismo para predecir el comportamiento de las personas. Por otro lado, el esfuerzo físico mantiene la alineación y se vincula con la agencia (reduciendo la percepción del esfuerzo al redireccionar la atención lejos de la propiocepción) dando lugar a un estado de excitación (arousal). Por último, la expresividad de los patrones musicales puede modular el esfuerzo físico: músicas con efectos activadores aumentan la cantidad de energía de una acción y músicas con efecto relajante la disminuyen, estableciéndose una transferencia de la energía sónica a la motora que conduce a la excitación.

En el capítulo 8 Leman desarrolla la hipótesis de que la interacción con la música es recompensada positivamente y que hay vínculos específicos entre los componentes de la interacción y los tipos de recompensa regulados por los procesos motivacionales. La predicción sensorio-motora está ligada a la agencia y el esfuerzo físico a la excitación, como se explicó anteriormente. La expresión está asociada a una valencia positiva y tiene efectos pro-sociales: la paleta emocional del repertorio permite la comunicación expresiva entre los miembros de una población. El efecto de recompensa que motiva a la interacción con la música está dado por la concurrencia de una excitación tranquila, una valencia positiva y una sensación de control. El ser humano posee un sistema de recompensa que permite predecir la recompensa de un estímulo determinado a través del modelo predictivo, lo que hace que las recompensas potenciales generen un efecto motivador (aunque es posible que el aprendizaje sensorio-motor disminuya su efecto placentero).

Leman cierra el libro en el capítulo 9 con dos tópicos. En primer lugar, analiza y proyecta las posibilidades de interacción expresiva de las tecnologías de mediación musical. Y en segundo lugar concluye que la predicción de patrones musicales, motores e intencionales no siempre es evidente o tiene una única interpretación. El enfrentamiento a esa indeterminación presente en la música durante la interacción expresiva implica aprender a lidiar con ciertas incertidumbres que pueden trasladarse a otros campos de la vida.

Las particularidades que toma el enfoque corporeizado de Leman han sido cuestionadas por algunas voces críticas que señalan que la idea de cuerpo como mediador, la división entre acción y percepción y el lugar central que ocupan los mecanismos-espejo entre sonido y gesto (Schiavio, 2014; Geeves y Sutton, 2014) suponen una dicotomía que contradice los principios de la cognición corporeizada. Si bien estos análisis son válidos, la idea de una comunión constitutiva e inseparable entre cuerpo y cognición y entre acción y percepción no ha dado 
lugar a un estudio de la experiencia musical profundo, específico y sistemático el desarrollado por Leman en El momento expresivo, cuyas aplicaciones van desde la enseñanza de instrumentos musicales hasta el desarrollo de tecnologías de mediación musical. La encrucijada es epistemológica: las unidades de análisis definidas y mensurables distorsionan la complejidad del mundo, pero el intento de conservar su pureza, evitando las categorías que permiten su investigación, nos mantiene apartados de la realidad y nos obliga a conformarnos con interpretaciones teóricas o hipotéticas.

Las dimensiones expresivas analizadas y medidas en los estudios reseñados en el libro son la articulación, la intensidad, algunos aspectos en relación al timbre y al tempo (timing) y los movimientos que codifican o decodifican esos patrones musicales. La expresión aparece como aquello que acompaña a ciertas características musicales estables (melodía, ritmo y armonía) y a las acciones que generan el sonido. Si bien hay muchas músicas y contextos de interacción que se desarrollan sobre este tipo de escenario (los estudios de Leman examinan la expresión en músicas clásico-románticas, en el jazz y en música Guqin), en otras prácticas musicales el componente expresivo puede tener otras peculiaridades: ¿cuáles son los movimientos expresivos de un músico cuyo instrumento es la computadora y cómo se codifican en la música? ¿dónde se encuentra la expresión musical en una cuerda de candombe? Habrá que evaluar si hay aspectos del modelo general propuesto por Leman que necesiten profundizarse o reformularse en función de las particularidades de cada contexto musical, definiendo ante todo en qué consisten sus aspectos expresivos.

Estas observaciones no descartan ni niegan los ambiciosos objetivos de Leman: la creación de varios modelos generales que explican diferentes aspectos de la experiencia musical (el comunicativo, el predictivo, el biológico, el sociocultural, el motivacional), la descripción del origen de la cultura desde un enfoque biológico y corporizado pero también comunicativo y social, y la organización bajo el paradigma enactivo de muchas ideas de la cognición corporeizada que permanecían desarticuladas. En resumen, El momento expresivo constituye un aporte valioso y controversial a las ciencias cognitivas de la música que aborda de forma integral los temas centrales del debate actual.

\section{Referencias}

Cross, I. (2010). La Música en la Cultura y la Evolución. Epistemus, 1(1), 9-19. Recuperado de http://revistas.unlp.edu.ar/Epistemus/issue/view/259.

Di Paolo, E. A. y Thompson, E. (2014). The enactive approach. En L. Shapiro. (Ed.), The Routledge handbook of embodied cognition (pp. 68-78). Nueva york, Estados Unidos: Routledge. 
Engel, A. K. (2010). Directive Minds: How Dynamics Shapes Cognition. En J. Stewart, O. Gapenne, E. A. Di Paolo. (Ed.), Enaction. Toward a New Paradigm for Cognitive Science (pp. 219-243). Cambridge, Estados Unidos: The MIT Press.

Fernández Morante, B. y Casas-Mas, A. (2016). Re-lecturas sobre Wundt y Seashore y nacimiento de AEPMIM. La psicología en la música y con los músicos. Epistemus, 4(1), 133-160. doi: 10.21932/epistemus.4.3062.1

Geeves, A. y Sutton, J. (2014). Embodied Cognition, Perception, and Performance in Music. Empirical Musicology Review, 9(3-4), 247-253. doi: 10.18061/emr.v9i3-4.4538

Leman, M. ([2008] - 2011). Cognición musical corporeizada y tecnología de la mediación. [I. C. Martínez, R. Herrera, V. Silva, C. Mauleón, D. Callejas Leiva (trads) Embodied music cognition and mediation technology]. Buenos Aires: SACCoM.

Martínez, I. C. (2014). La base corporeizada del significado musical. En S. Español, Psicología de la música y del desarrollo. Una exploración interdisciplinaria sobre la musicalidad (pp. 71-110). Buenos Aires (Argentina): Paidós.

Pozo, J. I. (1989). Teorías cognitivas del aprendizaje. Madrid, España: Ediciones Morata

Schiavio, A. (2014). Action. Enaction. Inter(en)action. Empirical Musicology Review, 9(3-4), 254-262. doi: 10.18061/emr.v9i3-4.4440

\section{Biografia de la autora}

\section{María Marchiano}

\section{maria.marchiano@hotmail.com}

María Marchiano es Profesora de Música con orientación en Composición egresada de la Facultad de Bellas Artes - UNLP. Desde el año 2014 participa en el proyecto de investigación "Los fenómenos tímbricos como herramienta de estudios de Instrumentación, Estilística y Creación musical" y desempeña tareas docentes en la cátedra Instrumentación y Orquestación de dicha facultad. Formó parte de diversos grupos musicales, entre los que se destacan el colectivo performático Ensamble Mulieres (2013-14) y las bandas Maniquí (2013) y Franca (2014-15), con las que grabó "Liquid Love" y "Franca", respectivamente. En el 2014 participó de la composición, interpretación y grabación de la música para el cortometraje "Viaje a la Luna" de Georges Méliès, encargada por el Planetario Ciudad de La Plata. Su obra "La Puta" (2013), compuesta y estrenada en el marco del seminario "El saxofón y sus posibilidades técnicas en el contexto de la Música Contemporánea", fue seleccionada para participar en el "Scanidinavian Saxophone Festival 2013". Actualmente se encuentra finalizando la Tesis de Grado para la obtención del título de la Licenciatura en Música con orientación en Composición, estudiando la carrera Analista Programador Universitario en la Facultad de Informática - UNLP, y realizando trabajos de investigación en la cátedra de Audioperceptiva 1 y en el Laboratorio para el Estudio de la Experiencia Musical (LEEM) en la Facultad de Bellas Artes. 